\title{
Effects of a Dependent Group Contingency on the Verbal Interactions of Middle School Students with Emotional Disturbance
}

\author{
Spencer D. Hansen \\ Davis School District, Farmington, Utah \\ Benjamin Lignugaris/Kraft \\ Utah State University
}

\begin{abstract}
This study examined the effects of a dependent group contingency to increase positive verbal interactions among nine middle school-aged males in a self-contained classroom. Prior to implementing the group contingency, the students received social skills instruction. A withdrawal experimental design was then used to evaluate the effects of the dependent group contingency. Students' positive verbal interactions increased and negative verbal interactions decreased with the implementation of the dependent group contingency. When the group contingency was faded, positive and negative interaction levels were maintained. The results are discussed in terms of developing positive interaction skills among youth with emotional disturbance and the application of dependent group contingencies with these students.
\end{abstract}

Social skills training with students with disabilities has enjoyed a long history spanning several decades (Cartledge \& Milburn, 1995; Hollinger, 1987; Reardon, Hersen, Foley, \& Bellack, 1979). Arguably, no single group of students has benefited more from social skills research than students with emotional disturbance. Students with emotional disturbance tend to have more antisocial behaviors (Merrell, Sanders, \& Popinga, 1993) and negative peer relationships (Asher \& Hymel, 1981) than other populations with disabilities. Developing positive peer relationships and prosocial behaviors depends on "explicit social instruction" (Hallenbeck \& Kauffman, 1995). Increasingly, general education teachers utilize group projects, cooperative grouping, and peer tutoring in their instruction (Salisbury, Gallucci, Palombaro, \& Peck, 1995). To be successful in these instructional arrangements, students must interact positively with their peers and evidence minimal negative or coercive interactions. For many students with emotional disturbances, how to interact positively with peers can be taught only with a carefully structured program that provides numerous opportunities for positive verbal interactions
among peers.
Strategies that employ "behavioral trapping" or "reciprocal interaction" are effective in helping students with emotional disorders overcome their social deficits (McConnell, 1987; Shores, 1987; Stokes \& Baer, 1977). Behavioral trapping occurs when newly learned social behaviors (e.g., request to play a game) are reinforced by related behaviors of others (e.g., cooperation), which in turn are reinforced and maintained by new patterns in interaction with the child receiving the intervention. Simply put, positive social interaction breeds reciprocal interactions from non-target peers who are likewise positive. In this continuum, students are naturally reinforced by peers for emitting appropriate social dialogue. This process can be employed for a host of social interaction deficits. In one study, behavioral trapping increased the duration of social interaction time among preschool students (McConnell, Sisson, Cort, \& Strain, 1991). The intervention strategy used a combination of social skills training and individual/group coaching that included prompts and praise. Individual coaching included prompts and praise that produced significant initial interactions among peers during free play, but did not increase the number of reciprocal 
interactions. Group coaching of each play group produced desired effects on peer behavior, but had less effect on the interactive behavior of target students. The effects of the combined social skills instruction and individual/group coaching continued during free play after the contingent praise was removed.

Other studies have used social skills training with reinforcement strategies to promote positive social interactions (Kamps, Tankersley, \& Ellis, 2000; Lo, Loe, \& Cartledge, 2002). Kamps et al. focused on increasing positive interactions and decreasing negative verbal interactions between kindergarten and first grade students during free play. A token economy was implemented after initial social skills training. The children participating in the study decreased inappropriate behavior including aggression, out-of-seat behaviors, grabbing, and negative verbal statements. The children also increased compliance to teacher directions and engaged in significantly more time in positive interactions with peers during play groups. The authors reaffirmed the need for "strong multiple interventions" paired with social skills training to provide positive social progress and reduce chronic aggressive behaviors (Kamps et al., p. 321). In another study, Lo et al. used social skills training combined with a grab bag that contained tangible reinforcers to reduce the antisocial behaviors of students who were at risk for emotional disturbance. Access was given to the grab bag when students obtained three flags for participating in class, demonstrating a social skill, or performing socially appropriate behaviors (e.g., paying attention, raising hand). The flags were also removed in a response contingency for inappropriate behavior. The results of this study indicated that a combination of social skills training and grab bag reinforcement effectively reduced the occurrence of antisocial behavior for the target students. Moreover, students used appropriate social skills in both the classroom and the lunchroom. The authors suggested, however, that a more direct intervention, such as a group contingency, might be more effective in generating positive verbal interactions among peers.

The available social skills research using group contingencies focuses on decreasing negative behaviors rather than increasing positive behaviors (e.g., Gresham \& Gresham,
1982; Page \& Edwards, 1978). The primary targets for the group contingency included decreasing student talk-outs, throwing objects, and out-of-seat behaviors. No studies have specifically addressed increasing positive behaviors to take the place of negative behaviors. In addition, the available research on group contingencies traditionally addresses general education students in elementary school settings (Brantley \& Webster, 1993; Crouch, Gresham, \& Wright, 1985). Few studies involving group contingencies have addressed middle school students or students with disabilities.

The purpose of this study was to investigate the effectiveness of social skills training and a dependent group contingency on the positive and negative verbal interactions of middle school students with emotional disturbance. This study was designed as an extension of previous studies of early elementaryaged students during free play situations. Specifically, we evaluated the effects of a social skills training followed by a direct intervention, a dependent group contingency, on the rates of positive and negative verbal interactions during independent activity time in a self-contained classroom for students with emotional disturbance.

\section{Methods}

\section{Participants}

The participants were nine males enrolled in a self-contained, special education classroom in a suburban junior high school. All participants were classified with emotional disturbances for special education purposes. Their behavioral characteristics and WoodcockJohnson reading and math percentile ranks are provided in Table 1. The children's ages ranged from 11-16 years, with a mean age of 13 . There were four students in the ninth grade, two in the eighth grade, and three in the seventh grade. During the course of the study, one ninth-grade student was released from the self-contained center at the end of his 45-day temporary Interim Alternative Educational Setting placement. Another student, also a ninth-grader, immediately took his place in the self-contained classroom; he was a foster child recently relocated into the district boundaries. One student did not complete the study; he 


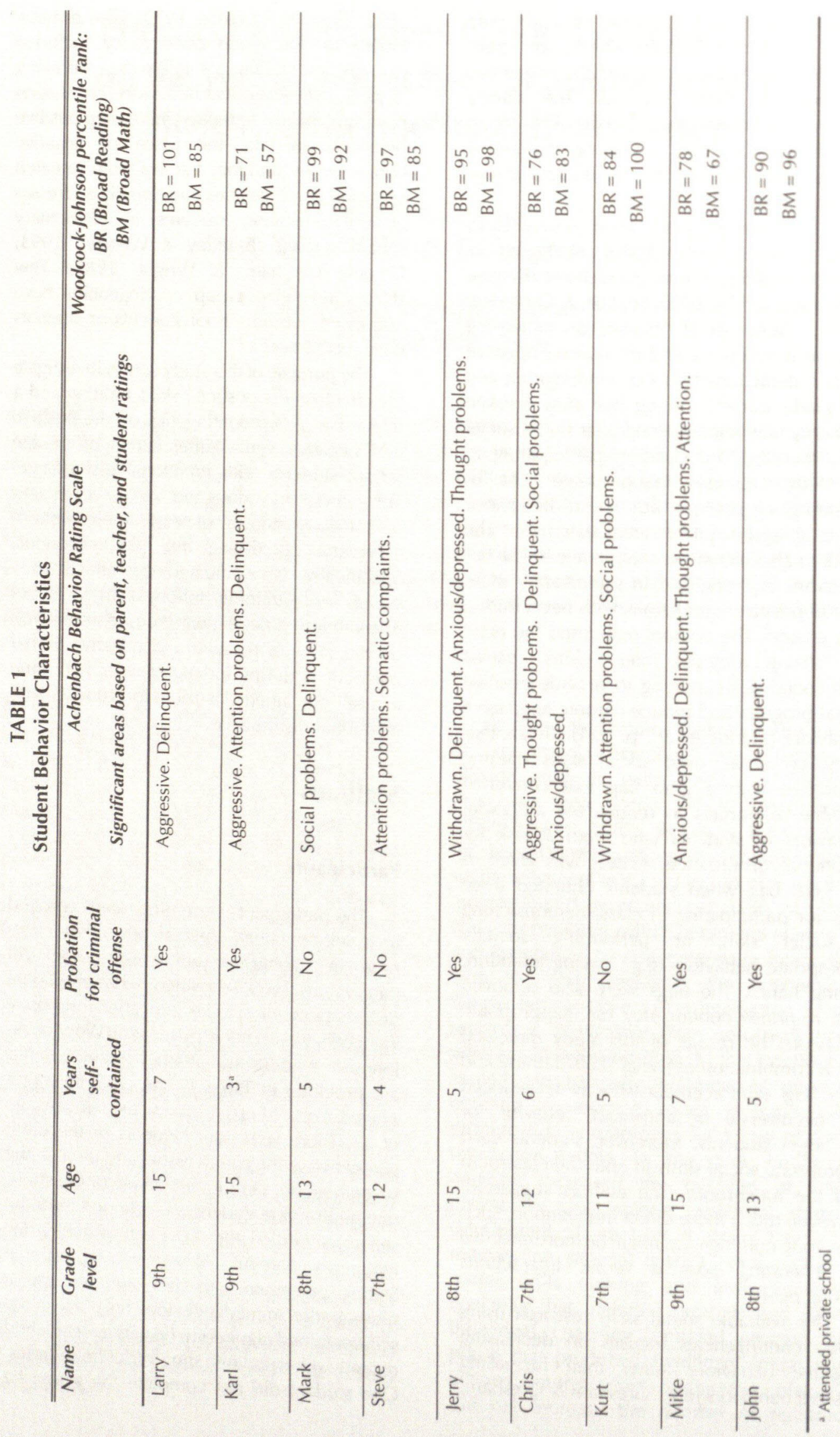

172 / February 2005 
exited the self-contained classroom when his family moved to another state. All nine students were in a self-contained classroom placement for at least one year prior to this study.

\section{Setting}

The study was conducted during fourth period math class in the self-contained classroom. The class was staffed by one fulltime licensed special education teacher and one full-time licensed special education paraeducator.

At the beginning of the math class, students went to their desks and awaited instruction. During the first five minutes of class, students were split into two groups: one high academicskill group and one low academic-skill group. After breaking into groups, students obtained their lessons, gathered scratch paper, and sharpened pencils. During the next 25 minutes, the teacher and paraeducator conducted mathematics lessons. New material was presented, and ample time was provided for guided and independent practice. During the remaining 15 minutes of the class, students pursued independent activities such as playing checkers or chess, drawing, coloring, chatting with other students, or reading.

The classroom management system was based on a points and level system (Cruz \& Cullinan, 2001) in which students earned privileges or restrictions based on their behavior. A low classroom rating resulted in increased restrictions with few privileges. Students on Level 1 could not leave their desks unless escorted. These students were also required to eat their lunch in the classroom and had limited opportunities to select freetime activities such as reading or drawing. In contrast, students on Level 4 could leave the classroom unescorted to run errands and go to the rest room. They frequently had opportunities to select free-time activities with the regular education student body and utilized all free-time activities. Levels were based on a point card that was taped to students' desks at the beginning of the day.

\section{Dependent Measures}

The two dependent variables in this study were rates of positive and negative verbal statements. The frequency of verbal statements was recorded within a one-minute, partial interval recording system. The 15-minute observational period was divided into oneminute intervals. The intervals were represented as blocks on the data collection form. Each block was then divided in half. Each negative statement during an interval was recorded on the left side of each block by marking the first letter of a student's name. Negative verbal interactions included criticizing, belittling, or antagonizing statements to peers. Examples of negative verbal statements included: "You're stupid"; "Get away from me"; "You freak"; I'm gonna beat you up"; and "You crybaby." Each positive statement was recorded on the right side of each block by marking the first letter of a student's name. Positive statements included compliments, encouragement, praise, or empathizing with a peer. Examples of positive verbal statements included: "Great job"; "You're awesome"; "I like the way you ... ."; "That's cool"; and "I'm sorry that happened to you." Movement from one interval to the next was signaled by a vibrating pager (Behavioral Dynamics Inc., 2003).

\section{Independent Measures}

Social skills instruction. During social skills instruction, students were taught how to give positive statements using the program Social Skills Strategies (Gawerski \& Mayo, 1989). First, students were taught the difference between positive and negative statements, the rationale for making those statements to peers, and what makes a good compliment. Students also learned that their tone of voice played a role in how peers received their compliments. Students role-played situations, first with the teacher and then with peers, to demonstrate their skill of giving positive statements. During role-play situations, the classroom teacher evaluated each student's performance in five different situations. These situations were: (a) greeting another student upon coming to school; (b) encouraging another student while helping him with schoolwork; (c) playing together during independent activity time; (d) sticking up for a fellow student when someone else puts him down; and (e) talking to people in the lunchroom. The teacher praised the students following a positive role-play.

Dependent group contingency. Each day, two class members were chosen randomly. The names of these individuals were not revealed to the class. For the class to earn a reward at the end of the day, the two class members were required to emit at least four positive 
statements to peers during the 15-minute independent activity period. The teacher used a small, square, dry erase board to tally positive statements as they occurred. On the top of the dry erase board, the teacher posted the minimum number of positive statements required from the group for that day. This goal was determined by multiplying the number of students by four. When a student emitted a positive verbal statement to a peer, the teacher tallied a mark on the dry erase board and praised that student. This provided students immediate feedback on their performance. At the end of the math class, students were told if they earned the reward for that day.

Potentially effective rewards were determined in advance by a reinforcer preference checklist. The checklist consisted of 20 possible tangible, edible, and natural rewards. Students were asked to number the items $1-20$ in the order they liked them (1 being the favorite, 20 being the least favorite). The checklist was completed before the study began and students were told that this would be used to obtain reinforcement ideas for the new semester. The items students selected most frequently included a $\$ 5$ bill, soda pop, and a 30-minute rest time in lieu of physical education class. The names of the items students identified as reinforcing were written on raffle tickets. The tickets were placed in a grab bag. During seventh period, each student selected a ticket from the grab bag to determine their reward on days that the class met the dependent group contingency criteria.

\section{Research Design}

The experimental design was a withdrawal design (Cooper, Heron, \& Heward, 1987). This was used to demonstrate the effect of the dependent group contingency on positive and negative verbal statements.

\section{Procedures}

The experiment consisted of four conditions: baseline, social skills training, dependent group contingency, and faded dependent group contingency.

Baseline. During the fourth period math class, the classroom teacher recorded the frequency of positive and negative statements to determine current statement levels among class members. All positive statements were followed by teacher praise, while negative statements were ignored. Baseline continued until the rate of positive and negative verbalizations was stable for at least three consecutive days for each student in the class.

Social skills training. After a stable baseline was established in the fourth period math class, social skills training was initiated during first period. Social skills training ended when all students demonstrated correct performance in the five role-play situations. The teacher collected data on positive and negative statements during fourth period math class throughout the social skills training condition. After the frequency of positive and negative statements stabilized, the dependent group contingency was implemented.

Dependent group contingency. Two target students were selected randomly as the dependent peers for the day. Initially, all students were briefed on the dependent group contingency and reminded of what qualified as a positive statement. When a student emitted a positive verbal statement, the teacher marked the student's verbalization on a data collection sheet and tallied a mark on a dry erase board in the front of the classroom. The teacher then praised the student. When a student emitted a negative verbal statement, the teacher simply marked the verbalization on the data collection sheet. Importantly, the teacher did not acknowledge the student's verbalization. If the randomly selected students met the criteria of four positive statements for the day, each student selected a reward from the grab bag at the end of the school day.

Faded dependent group contingency. After behavior stabilized for three consecutive days, the original dependent group contingency was implemented without the teacher's dry erase board record. Only teacher praise was provided for positive verbal statements. Students were told that the intervention would be randomly implemented on three days instead of five days during the school week. When the procedure was implemented, the dependent group contingency was applied on two of the first four days of the school week. When students arrived on the last day, they knew that the dependent group contingency was available. Since students could predict one or more reward days, the fade procedure was modified.

Modified faded group contingency. In the modified fade procedure, a single die was rolled if students met the dependent group contingency for that day. If students rolled a 3 , 
4,5 , or 6 , then all students received a reward. After the frequency of positive and negative statements stabilized for three consecutive days, students needed to roll a 5 or 6 to obtain the reward. Throughout the fading procedure, praise continued for each positive statement.

\section{Interobserver Agreement}

Interobserver agreement was calculated by comparing the teacher's record with a paraeducator's record. The paraeducator observed the targeted class period on $20 \%$ of the days distributed randomly across experimental conditions. The paraeducator was trained for two, one-hour sessions in which multiple examples and non-examples of the target behaviors were demonstrated. At the beginning of the reliability observations, the teacher and paraeducator synchronized two vibrating pagers. The paraeducator then sat in the back of the room when the teacher took his usual place at the front of the room. The teacher and paraeducator then recorded positive and negative statements concurrently. Agreement was determined by comparing the frequency of positive and negative statements within each interval for each student. The number of agreements was divided by the number of agreements and disagreements and multiplied by 100 within each interval and then a mean was calculated across intervals to obtain an interobserver agreement index for the observation session. The interobserver agreement mean and range across observation sessions for positive and negative statements was $97 \%(89 \%-100 \%)$ and $85 \%(43 \%-100 \%)$, respectively.

\section{Results}

The rate of positive and negative statements among students in the class is presented in Figures 1-9. During the initial baseline, only two of eight students emitted positive statements. The average rate of positive statements per minute during baseline was 0.02 and 0.01 for Larry and Steve, respectively. No other students emitted positive statements to peers. In contrast, all students emitted at least one negative statement to a peer during the initial baseline phase. The average rate of negative statements per minute per student was 0.15 during baseline. In particular, Mark (mean $=0.20 / \mathrm{min}$.), Karl (mean $=0.30 /$ min.), and Larry (mean $=0.56 / \mathrm{min}$.) emitted

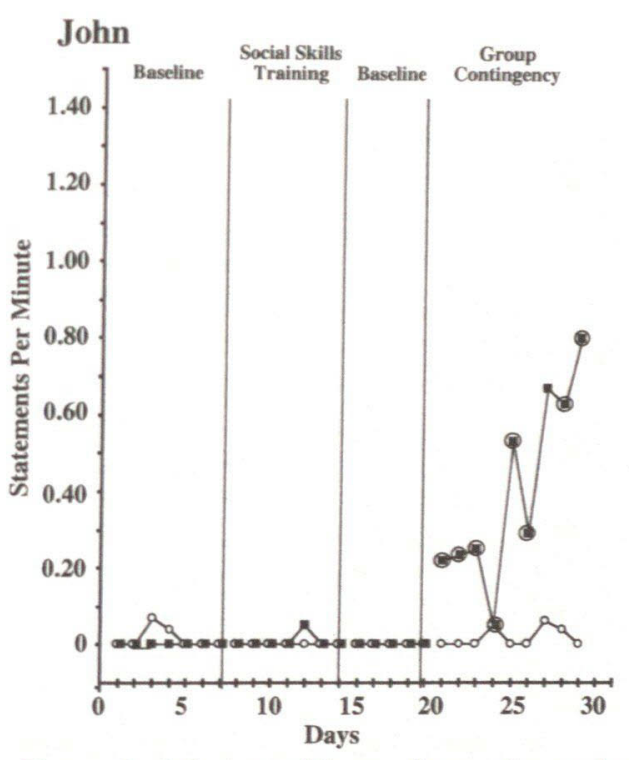

Figure 1. John's positive and negative verbal statements during baseline, social skills training, and group contingency conditions.

between 5 and 11 times more negative statements to peers than the average of the remaining five students in the class (mean $=0.04 / \mathrm{min}$ ).

\section{Social Skills Training}

During social skills training, the number of students emitting positive statements increased to five out of eight students. However, these students emitted a very low rate of positive statements. The number of students emitting negative statements to peers decreased from six to eight. The average rate of negative statements per minute per student was the same as during baseline (mean $=0.15 / \mathrm{min}$ ). The two students who emitted the lowest rate of negative statements during baseline did not emit any during the social skills condition. Moreover, Larry (mean $=0.55 / \mathrm{min})$, Mark $($ mean $=0.30 /$ $\min )$, and $\operatorname{Karl}(\operatorname{mean}=0.26 / \mathrm{min}$ ) continued to emit negative statements at a higher rate than the other students in the class.

\section{Baseline}

During the second baseline procedure, only one of the eight students emitted positive statements to peers. Conversely, six of eight students continued to emit negative statements to peers at a mean rate of 0.15 negative statements per minute per student. Interestingly, Steve's and Jerry's rates of negative statements increased slightly as compared to baseline 


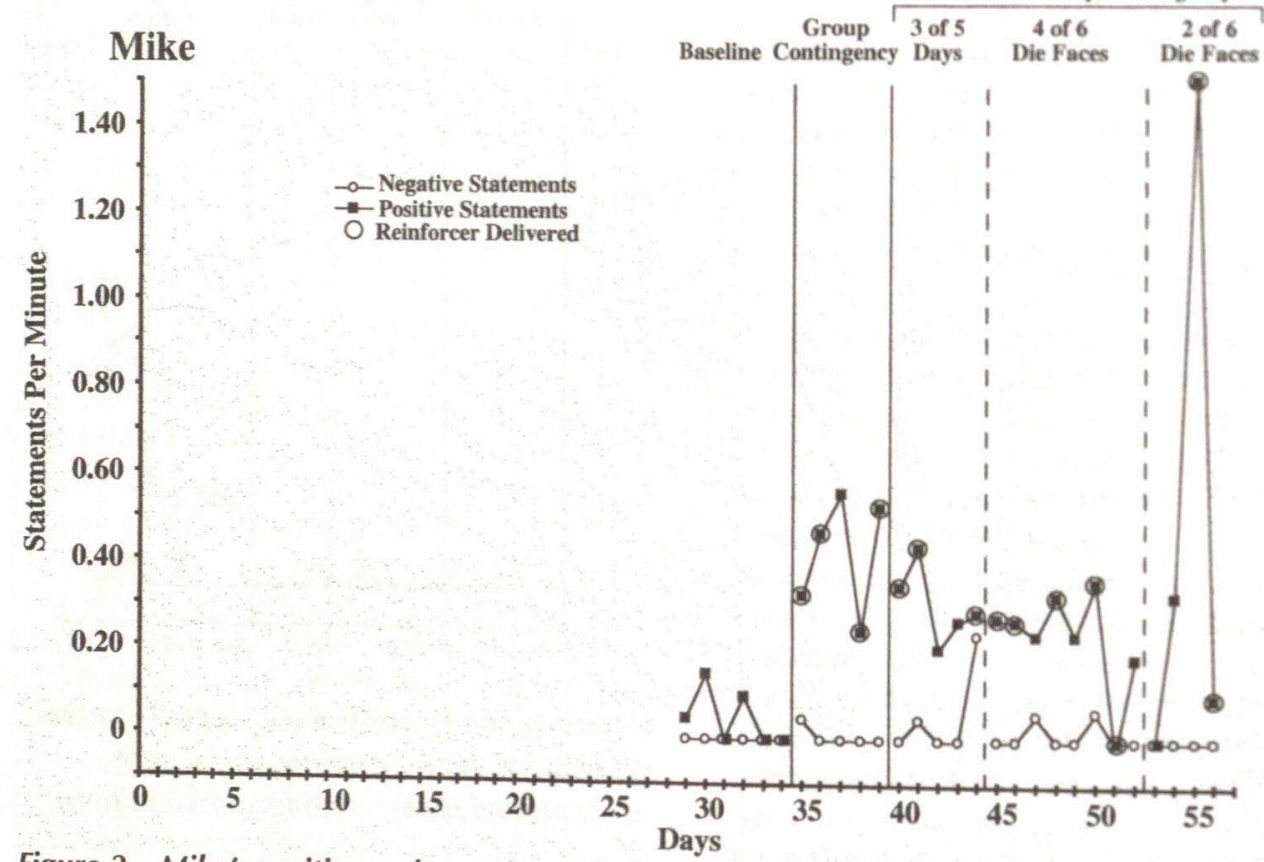
Figure 2. Mike's positive and negative verbal statements during baseline, social skills training,
group contingency, and fading conditions.

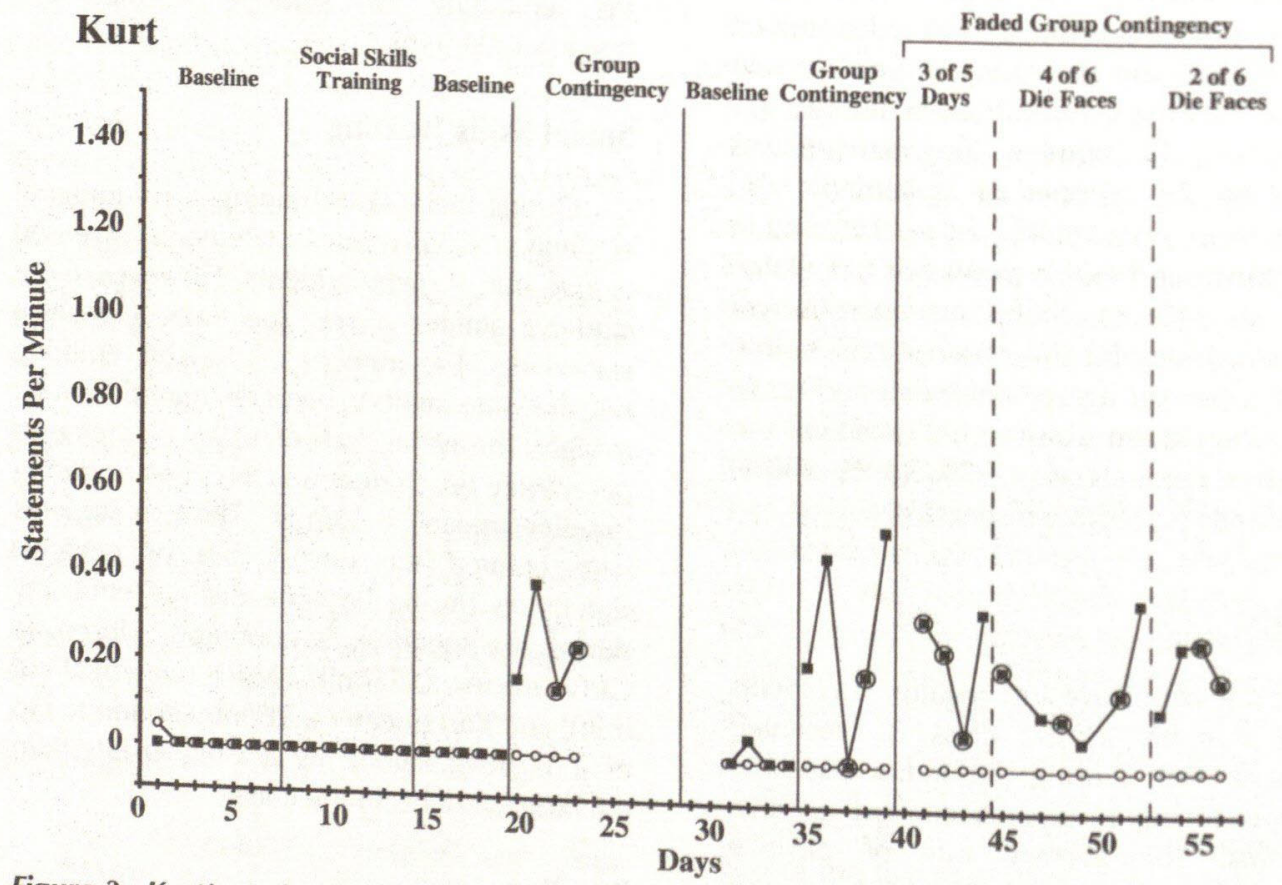

Figure 3. Kurt's positive and negative verbal statements during baseline, social skills training,
group contingency, and fading conditions. and social skills training, while Larry (mean=
$0.49 / \mathrm{min}$ ), Karl (mean $=0.25 / \mathrm{min}$ ) (mean $=0.22 / \mathrm{min}$ ) rates of negative continued to produce high continued to give notements. John and Kurt peers during this phase.

\section{First Group Contingency}

In the first group contingency phase, the rate of positive statements increased for all students. The average rate per minute per student was 0.34 . Three students produced 
a higher rate: Larry $($ mean $=0.46 / \mathrm{min})$, John $($ mean $=0.43 / \mathrm{min})$, and Steve $($ mean $=0.40 /$ min). Students obtained eight out of nine possible reward days for this condition. It is important to note that all students at least tripled their positive statement output as compared to previous conditions. Conversely, the rate of negative statements diminished. While six of eight students emitted negative statements, the average rate per minute per student decreased from 0.15 during social skills to 0.03 .

\section{Baseline}

In the third baseline phase, the rate of positive statements decreased dramatically. All students except Kurt began the phase with a rate of positive statements that was equal to or higher than one or more days during the group contingency. However, the rate decreased rapidly to previous baseline levels for all students except Jerry, who averaged 0.12 positive statements per minute during the last three sessions in the phase. Steve $($ mean $=0.29 / \mathrm{min})$ maintained the highest rate of positive statements. The average rate of positive statements per minute per student was 0.08. Interestingly, there is consistency in the rate of negative statements emitted to peers. In this phase, six of eight students emitted negative statements. The average rate of negative statements per minute per student was 0.04 , similar to the previous group contingency phase.

\section{TABLE 2}

Percentage of Increased and Decreased Performance After Reward Days

\begin{tabular}{lcc}
\hline \hline Name & Increase & Decrease \\
\hline John & $66 \%$ & $34 \%$ \\
Jerry & $65 \%$ & $35 \%$ \\
Steve & $59 \%$ & $41 \%$ \\
Larry & $50 \%$ & $50 \%$ \\
Kurt & $50 \%$ & $50 \%$ \\
Mike & $38 \%$ & $62 \%$ \\
Chris & $36 \%$ & $64 \%$ \\
Karl & $33 \%$ & $67 \%$ \\
Mark & $30 \%$ & $70 \%$
\end{tabular}

\section{Dependent Group Contingency}

During the second group contingency phase, the rate of positive statements to peers increased for all eight students. The average rate per minute per student was 0.32 . Three students exceeded the average rate of positive statements by emitting more than the other five students. Steve $($ mean $=0.43 / \mathrm{min}$ ) remained the leader in giving compliments, while Karl and Mike increased their rate of positive statements to a mean of $0.43 / \mathrm{min}$. On four of five days, students were eligible for a reward. Negative statements remained low with five of eight students emitting negative statements at an average rate of 0.03 statements per minute per student.

\section{Faded Dependent Group Contingency}

During the initial fade procedure, the number of positive statements emitted to peers decreased. All students continued to make positive statements with an average rate of 0.28 statements per minute per student, 0.04 lower than group contingency levels. Three students continued to emit more positive statements than other students in the class. Steve emitted an average of 0.55 positive statements per minute. Mark emitted an average of 0.35 positive statements per minute. Mike emitted an average of 0.31 positive statements per minute. Only four of seven students emitted negative statements during the fade procedure, with an average rate of 0.03 statements per minute per student.

In this phase, students earned three of five possible reward days. The two days without reward occurred on the third and fourth days of the week. During these two days, three students increased their positive statements, three students decreased their positive statements on the first day and then increased them on the second day, and one student decreased his rate of positive statements for one day and was absent the second. In contrast, negative statements for the class remained low, with five of eight students emitting negative statements to peers with an average rate of 0.03 statements per minute per student. It is important to note that the last data point in the initial fade procedure is an aberrant point. Due to a flaw in the fade procedure, students deduced the last reward day in the fade sequence. Hence, for all students there is a reversal of a declining 


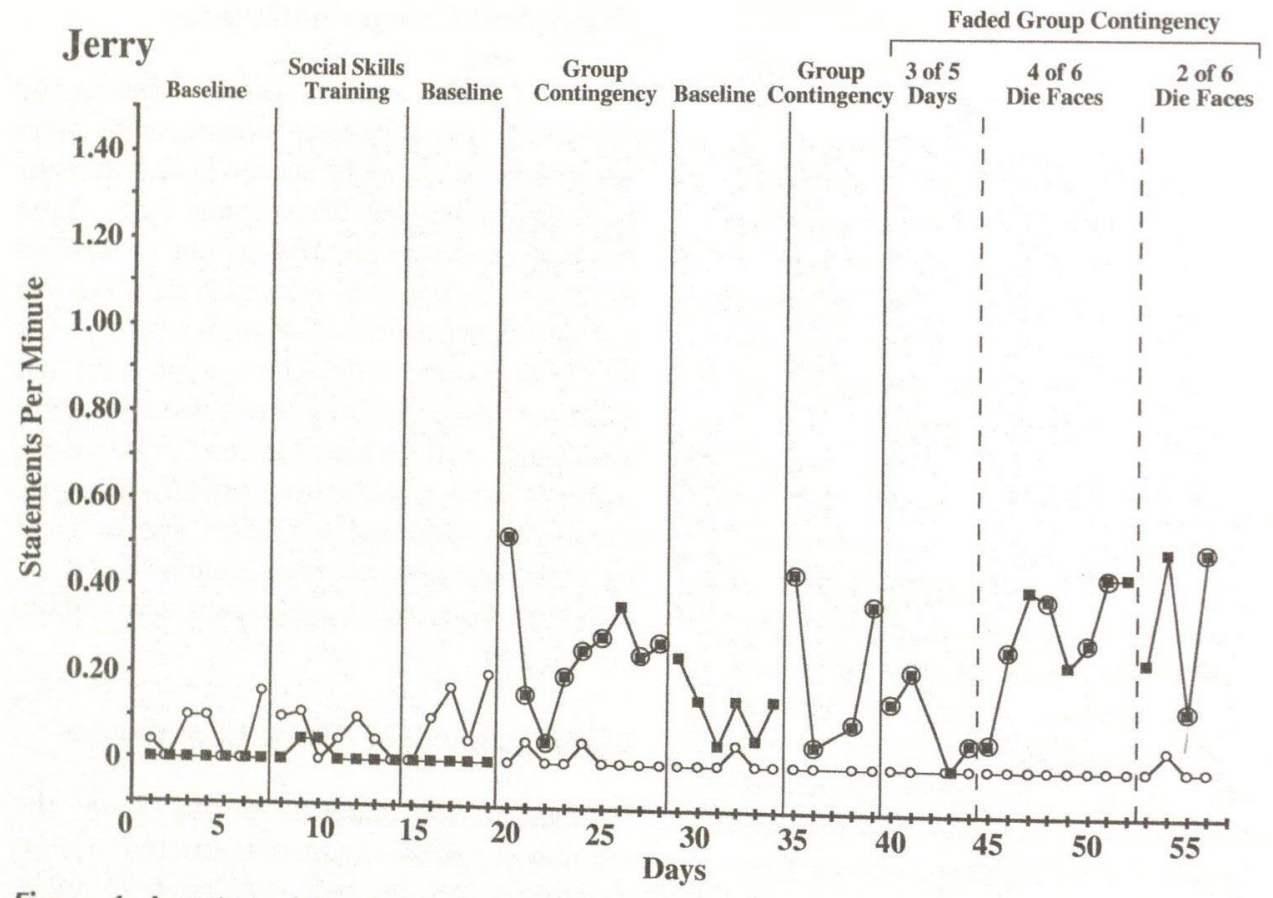
Figure 4. Jerry's positive and negative verbal statements during baseline, social skills training,
group contingency, and fading conditions.

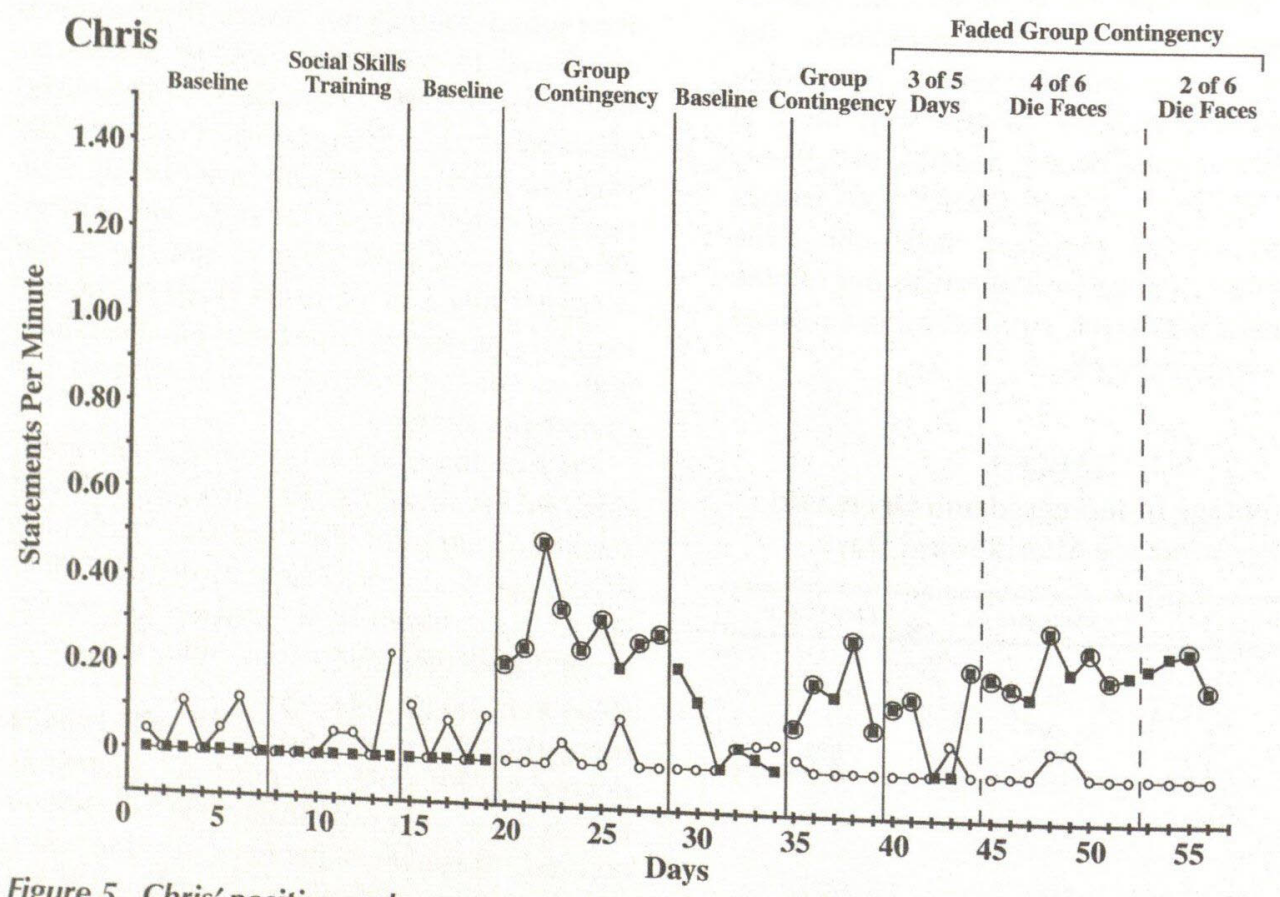
Figure 5 . Chris' positive and negative verbal statements during baseline, social skills training,
group contingency, and fading conditions.

trend in positive statements. Without that aberrant data point, it is possible that the declining trend in the initial fade procedure would continue.

\section{Modified Faded Group Contingency}

During the modified fade procedure, the frequency of positive statements stabilized. All students continued to emit positive statements at an average rate of 0.28 statements per minute per 


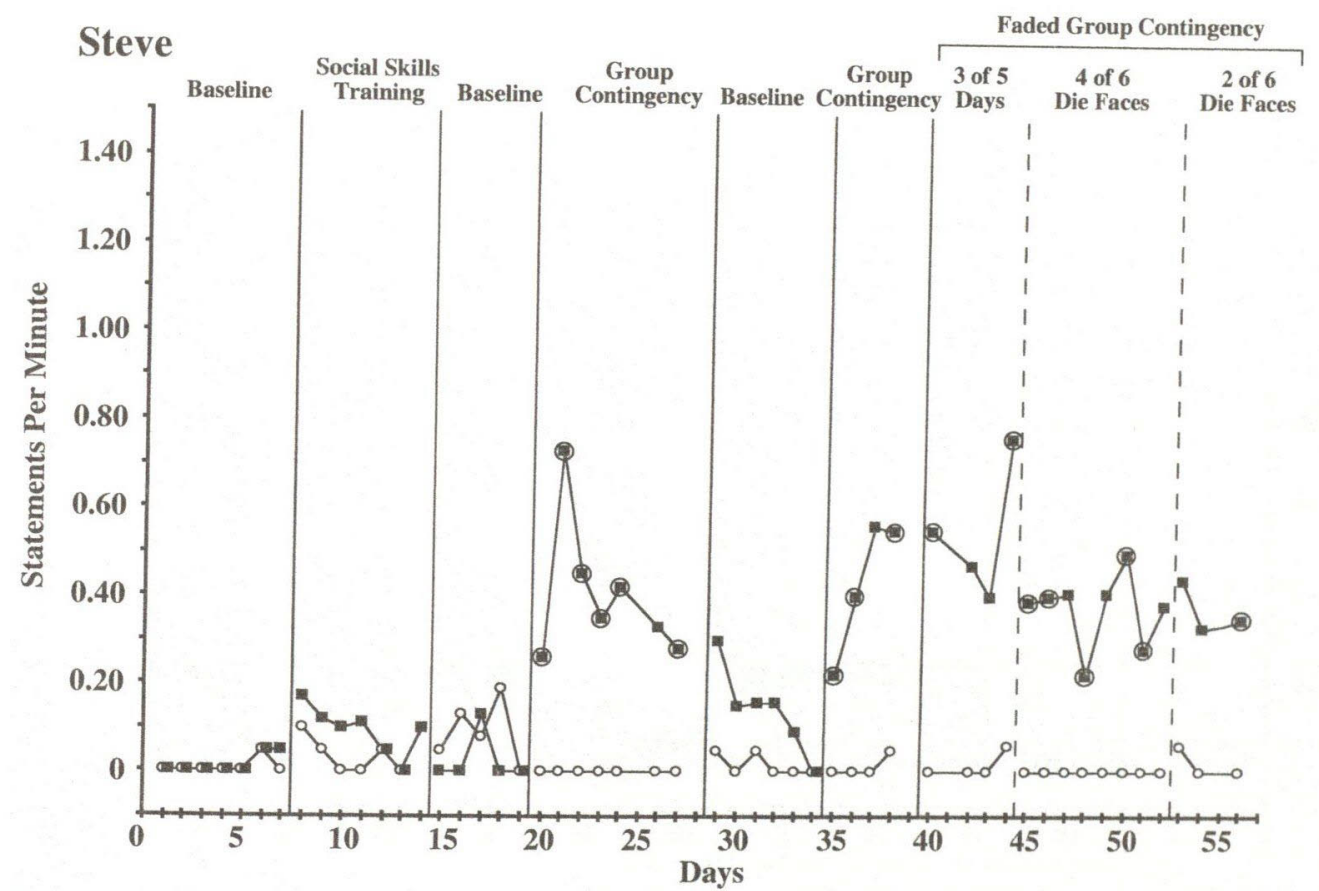

Figure 6. Steve's positive and negative verbal statements during baseline, social skills training, group contingency, and fading conditions.

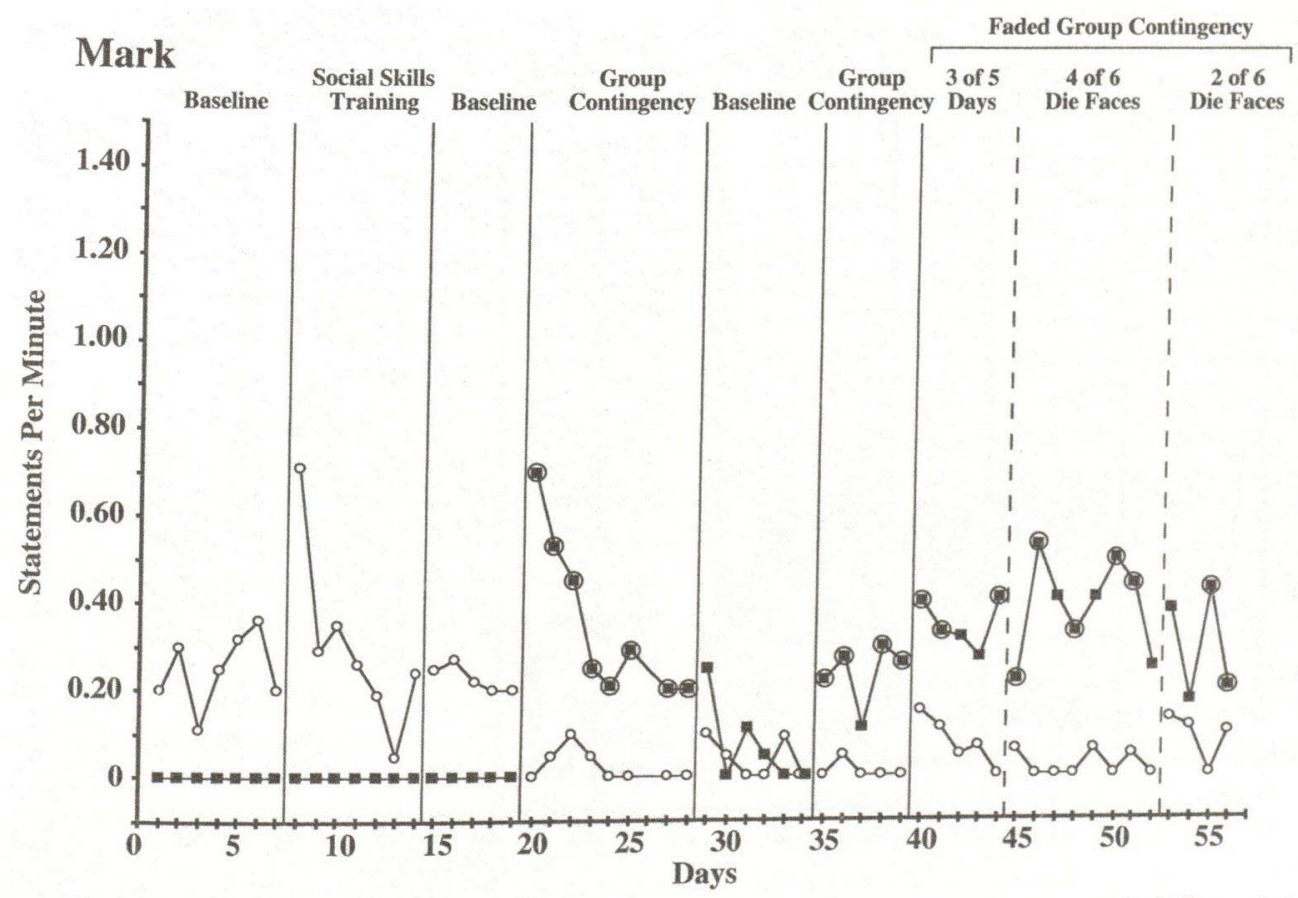

Figure 7. Mark's positive and negative verbal statements during baseline, social skills training, group contingency, and fading conditions.

student, the same as the initial fade procedure. Steve $($ mean $=0.37 / \mathrm{min})$, Mark $($ mean $=0.36 /$ $\mathrm{min})$, and Mike (mean $=0.31 / \mathrm{min}$ ) continued to emit high rates of positive statements. Jerry's average rate of positive statements was three times his average rate during the initial fade procedure. During the modified fade, students were rewarded on 7 of 12 possible reward days. Conversely, six of seven students continued to consistently emit low rates of negative 


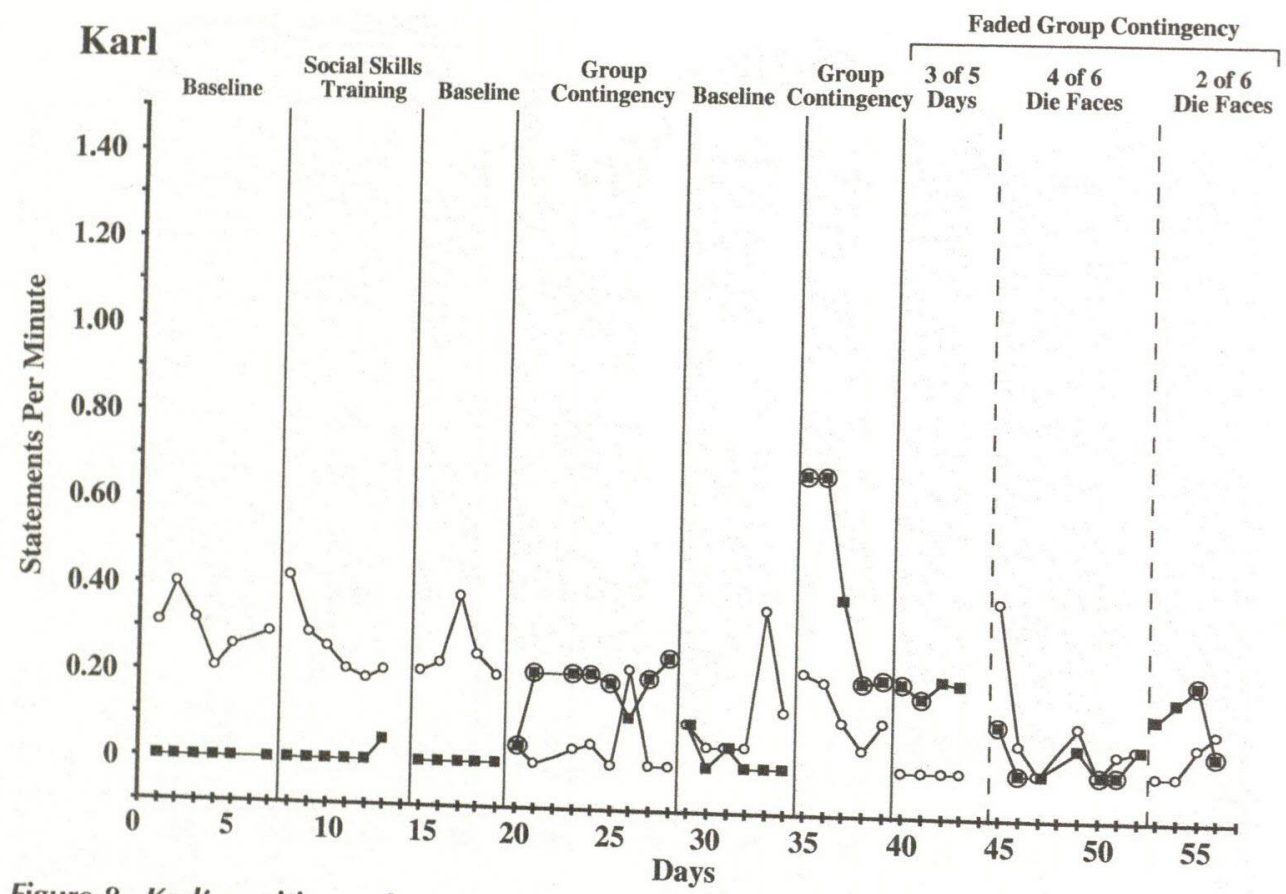

Figure 8 . Karl's positive and negative verbal statements during baseline, social skills training,
group contingency, and fading conditions.

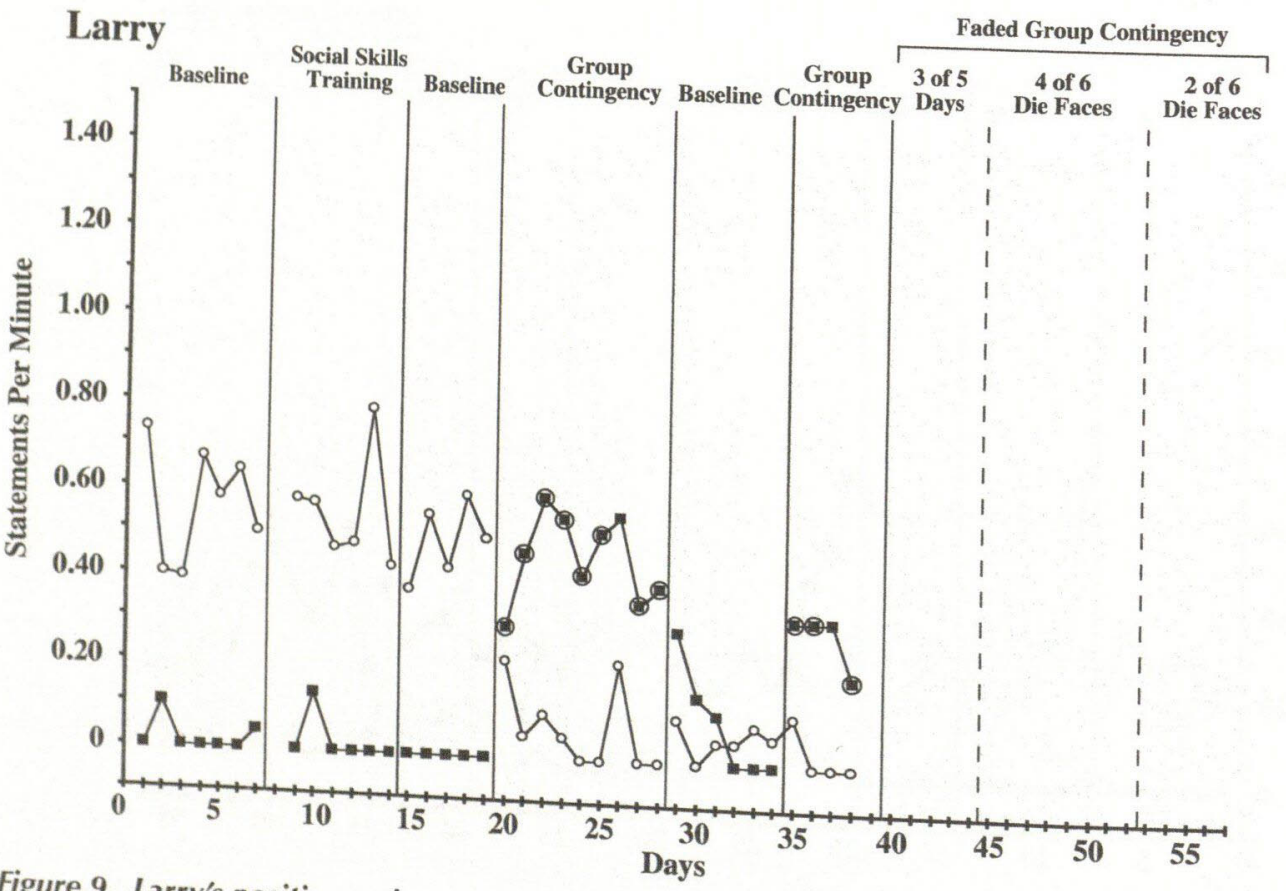

Figure 9. Larry's positive and negative verbal statements during baseline, social skills training,
group contingency, and fading conditions.

statements to peers, with an average rate of 0.02 statements per minute per student, the lowest negative rate of the study.

\section{Performance Following Reward and No-Reward Days}

The purpose of this analysis is to examine if increases in performance were correlated 
with days on which students earned rewards during the group contingency conditions. Table 2 presents the percentage of increased and decreased performance after reward days for each student. The students are listed in order from the student who increased most frequently following reward days to the student who decreased most frequently following reward days. John, Jerry, and Steve produced more positive statements the day after a reward day. Conversely, Mike, Chris, Karl, and Mark decreased their positive statement output more often on the day following a reward. During the initial group contingency procedure, only one day resulted in no reward. On the following day, four of six students (two students were absent that day) decreased the rate of positive statements to peers. No other trends were evident from this analysis. It is important to note that throughout the course of the study, no student consistently increased or decreased their rate of positive statements on days following a reward.

\section{Discussion}

The findings indicate that social skills training on giving positive statements to peers, paired with a dependent group contingency, not only increased and maintained the number of positive statements emitted to peers but also effectively decreased the rate of negative statements emitted to the same peers. Furthermore, for students with emotional disturbance, a dependent group contingency is a viable procedure for maintaining an acceptable level of positive statements to peers, thus enhancing their social development. Interestingly, social skills training had little effect on the rate of students' negative statements. Rather, negative statements decreased when the group contingency conditions were implemented.

Initially, students did not emit positive statements to peers. During baseline conditions, sarcasm and demeaning comments prevailed in student-to-student interactions. Any attempt at a positive statement was met with harsh criticism from the receiving peer or group of peers.

During social skills training, students indicated that saying positive things required more effort than saying negative things. During the initial social skills role plays, only two out of eight students demonstrated clear positive statements to peers. The remaining students produced responses like: "Nice ... uh ... face?"; "Nice buck teeth" (sarcasm); and "You're not as bad as ..." (putting someone else down). Repeated practice was required to get even the most basic positive statement form of "I like your ...." Even after completing all six role plays, these students' positive statements were still awkward, stilted, and repetitive.

In the initial group contingency condition, there was a dramatic increase in the rate of positive statements. However, the statements were very basic, rudimentary positive statements. Almost exclusively, the singular form of "I like your ..." was used to convey a positive statement; very rarely was there any deviation from this pattern. Many times, a positive statement was met by awkward silence on the part of the receiving peer or peers. At times, conversation between or among peers was halted because a student emitted a positive statement.

In the second group contingency, the "I like your . .." pattern continued to be used extensively. Steve was the only student who deviated from this form. He readily created his own positive statements, such as "You are a good friend" or "You have a great sense of humor."

During the fading procedure, the quality of positive statements changed. Students started to branch out from their "I like your ..." form to other forms such as: "I like your cool clothes"; "Is that a new jacket? I like it a lot"; and "I like your hair. It's real spiky." Two new patterns started to emerge during the fading condition. Students began to use adjectives with their stilted "I like your ..." form. They would refer to "cool" toys or "tough" shirts, or even "expensive" pants. In addition, a pattern of reciprocal interactions or behavioral trapping became prevalent. When student A said, "I like your Nike shoes; wish I had a pair," student B would say, "Thanks. I like your Game Boy. Can I check it out?" The initial statement was a natural reinforcer that encouraged future dialogue. While the rate (quantity) of positive statements decreased in the fade condition, the quality of positive statements began to vary, and the positive statements were used to initiate conversations.

Throughout the course of this study, the quality and quantity of positive statements continued to improve for all students. Conversely, the rate of negative statements across students throughout the study decreased 
and remained at a low rate for each successive study condition. When a student emitted a negative statement, that student was ignored by the teacher and assistant. It is possible that a high rate of rewarded positive statements was not compatible with high rates of negative statements. That is, students during the math period found themselves spending more time meeting the positive statement contingency. This left little time for emitting negative statements to peers. They simply could not emit acceptable rates of positive statements and maintain the rate of negative statements.

At the conclusion of the study, students were asked informally about their experience during the study. All students indicated that they enjoyed the classroom more when people were giving compliments. While they indicated that it was "kind of weird at first" to give positive statements to each other, they concluded that it made them feel good to give and to receive compliments. Moreover, five of seven students stated that they would like this pattern to continue.

When implementing a dependent group contingency, teachers should monitor how students react when one student blocks the reward for the entire group (Packard, 1970). In this study, there was some finger-pointing when the reward was not obtained. Students attempted to identify who blocked the reward for the group. However, the structure of the dependent contingency did not permit students to ascertain the guilty party. There were never any threats or physical confrontations when the group reward was not obtained. In fact, there was a large amount of camaraderie among students throughout the study. It is interesting to note that the three students (Larry, Karl, and Mark) who emitted the most negative statements during the baseline conditions became the positive leaders of the group. These students encouraged and reminded other students to emit positive statements so that they could obtain a reward. Moreover, very little of their encouragement was negative. As long as the reward was obtained, Larry, Karl, and Mark remained positive. When the reward was not obtained, they tried to identify who was at fault. On the following day, these students always came back to school positive, reminding the others to emit the required four statements during math class to get their reward.

It is also important to note that the dependent group contingency used in this study was not implemented as the only intervention in the self-contained classroom. The intervention was used in conjunction with a structured level system to maintain student behavior while at school. It is possible that the level system in some way affected the results of the study. Prior to the study, students were rarely kind to each other and were rarely rewarded for acts of kindness. Likewise, negative statements were not penalized, with the exception of threatening language, insults combined with profanity, or slurs about ethnicity or sexual orientation. Furthermore, there was no attempt to teach students in the classroom to give positive statements to peers prior to the study.

It appears that there were two factors that influenced the effects of the dependent group contingency. First, the teacher attempted to praise each positive statement. In addition, each positive statement was tallied on a dry erase board visible to students. During the intervention and fade procedures, the rate of positive statements was so fast that the teacher could not praise every positive comment. Therefore, students often had difficulty tracking whether their positive statement was recorded and whether they met the four statement criteria. Since students were not sure whether they met criteria, they would often emit more than four positive statements. During the group contingency procedures, Mark and Jerry often waited for a pause in the positive statements to emit their required statements. Thus, they could keep track of their statements and observe whether the teacher noted them on the tally board. This behavior continued during the fading procedures even when the tally board was no longer in use. The other students, however, continued to emit more than the necessary criteria. Thus, while the tally marks helped students keep track of their positive statements, the group posting strategy disguised the individual contingency used to make reward decisions. It is likely this procedure cont:ibuted to positive statement rates higher than the necessary criteria. Future research could utilize a bonus clause for the student who makes the most positive statements. This could further accentuate the frequency of positive statements.

Second, the reinforcement used in the dependent group contingency might have enhanced the observed effects. Students were given a plethora of edible and tangible reinforcements to choose from when they 
met the group contingency criteria. There was a larger variety of reinforcers than those available with any other intervention used in the classroom to date. One item, a $\$ 5$ bill, appeared to be more reinforcing than other items in the reinforcer menu. On two random days during intervention phases and once during the fade procedure, a $\$ 5$ bill was put in the grab bag on a reward day. Students frequently talked about the $\$ 5$ bill and repeatedly asked if the $\$ 5$ bill was in the grab bag for that day. When a student obtained the $\$ 5$ bill on a reward day, other students were visibly excited. One particular student, Karl, was highly motivated by the opportunity to obtain the $\$ 5$ bill until the fade procedure. Furthermore, it is possible that the effect of the rewards was enhanced by the reward procedure. That is, students were motivated by the game of chance inherent in the grab bag. Thus, the potency of the reinforcers, combined with the random nature of the grab bag, likely impacted the effectiveness of the dependent group contingency.

Within the study, two separate fading procedures were implemented. The first procedure was an interval method that included three reward days out of a fiveday school week. These days were chosen randomly, and students were not aware which were reward days and which were not. Most of the students decreased the number of positive statements given to peers during this fade procedure. Many students attempted to guess the reward days. To compensate for this, the fading procedure was altered. A random ratio method was utilized by rolling a die to determine if a reward was obtained for that day. The students seemed to enjoy the game of chance and maintained a higher level of positive statements during this fading procedure than the previous fade procedure.

This study raises a need for further research in several areas. First, additional research is needed on enhancing the quality of positive statements among peers. When this study started, many students did not know how to give a positive statement to peers. By the end of the study, the students' skill level had increased but still did not include a broad variety of statements. The dependent group contingency needs to be modified to require more varied responses when emitting positive statements, thus increasing the students' repertoire of positive verbal language.
Second, many of the items that were used as reinforcement during the group contingency were expensive ( $\$ 5$ bill) or timeconsuming (e.g., shooting basketball). While the frequency of reinforcement was faded, the quality of the reinforcers remained constant. Additional research is needed to determine if a reduced quality of reinforcement within a dependent group contingency structure would effectively increase positive statements among self-contained youth with emotional disturbance.

Third, this study addressed only the extent to which the participants' positive peer statements increased and negative peer statements decreased. The effect on the students' academic performance, if any, was not addressed. Future researchers should assess whether improvements in the classroom climate gained by increasing positive verbal interactions also results in improvements in academic performance.

The modified fade procedure (e.g., dierolling) needs to be studied more extensively and in varied settings. It is evident through this study that the die-rolling game worked well with this group of students. This procedure might also be used with other groups of middle-school aged youth to determine if it is equally viable.

In summary, a dependent group contingency systems can be a valuable intervention to use with youth with emotional disturbances. It may be considered a "strong intervention," capable of breaking the negative peer interactions typically found in individuals with emotional disturbances. Explicit social instruction is not enough to give these individuals the social repertoire they need. More research is needed on the use of less intensive reinforcers within group contingency systems, on fading procedures, and with other youth with emotional disturbance.

\section{References}

Asher, S. R., \& Hymel, S. (1981). Children's social competence in peer relations: Sociometric and behavioral assessment. In J. D. Wine \& M. D. Syme (Eds.), Social Competence (pp. 125-151). New York: Guilford.

Behavioral Dynamics Inc. (2003). MotivAider. Thief River Falls, MN.

Brantley, D., \& Webster, R. (1993). Use of an independent group contingency management system in a regular education setting. Psychology in the Schools, 30, 60-66. 
Cartledge, G., \& Milburn, J. F. (1995). Teaching social skills to children and youth: Innovative approaches (3rd ed.). Boston: Allyn and Bacon.

Cooper, J. O., Heron, T. E., \& Heward, W. L. (1987). Applied Behavior Analysis. Columbus, $\mathrm{OH}$ : Merrill Publishing.

Crouch, P., Gresham, F., \& Wright, W. (1985). Interdependent and independent group contingencies with immediate and delayed reinforcement for controlling classroom behavior. Journal of School Psychology, 23, 177-187.

Cruz, L., \& Cullinan, D. (2001). Awarding points, using levels to help children improve behavior. Council for Exceptional Children, 33, 16-24.

Gawerski, M., \& Mayo, P. (1989). SSS: Social skills strategies. Eau Claire, WI: Thinking Publications.

Gresham, F., \& Gresham, G. (1982). Interdependent, dependent and independent group contingencies for controlling disruptive classroom behavior. The Journal of Special Education, 16, 101-110.

Hallenbeck, B. A., \& Kauffman, J. M. (1995). How does observational learning affect the behavior of students with emotional or behavioral disorders? A review of research. Journal of Special Education, 29, 45-71.

Hollinger, J. D. (1987). Social skills for behaviorally disordered children as preparation for mainstreaming: Theory, practice, and new directions. Remedial and Special Education, 8, 17-27.

Kamps, D., Tankersley, M., \& Ellis, C. (2000). Social skills interventions for young at-risk students: A 2-year follow-up study. Behavioral Disorders, $25,310-324$.

Lo, Y., Loe, S. A., \& Cartledge, G. (2002). The effects of social skills instruction on the social behaviors of students at risk for emotional or behavioral disorders. Behavioral Disorders, 27, 371-385.

McConnell, S. R. (1987). Entrapment effects and the generalization and maintenance of social skills training for elementary school students with behavior disorders. Behavioral Disorders, 12, 252-263.

McConnell, S. R., Sisson, L. A., Cort, C. A., \& Strain, P. S. (1991). Effects of social skills training and contingency management on reciprocal interaction of preschool children with behavioral handicaps. The Journal of Special Education, 24, 473-495.

Merrell, K. W., Sanders, D. E., \& Popinga, M. R. (1993). Teacher ratings of students' social behavior as a predictor of special education status: Discriminant validity of the school social behavior scales. Journal of Psychoeducational Assessment, 11, 220-231.

Packard, R. (1970). The control of "classroom attention": A group contingency for complex behavior. Journal of Applied Behavior Analysis, 3, 13-28.

Page, D., \& Edwards, R. (1978). Behavior change strategies for reducing disruptive classroom behavior. Psychology in the Schools, 15, 413-418.

Reardon, R. C., Hersen, M., Foley, J. M., \& Bellack, A. S. (1979). Measuring social skill grade school boys. Journal of Behavioral Assessment, 1, 183-195.

Salisbury, C. L., Gallucci, C., Palombaro, M. M., \& Peck, C. A. (1995). Strategies that promote social relations among elementary students with and without severe disabilities in inclusive schools. Exceptional Children, 62, 125-137.

Shores, R. E. (1987). Overview of research on social interaction: A historical and personal perspective. Behavioral Disorders, 12, 233-241.

Stokes, T. F., \& Baer, D. M. (1977). An implicit technology of generalization. Journal of Applied Behavior Analysis, 10, 349-367.

AUTHOR'S NOTE

Correspondence regarding this article should be sent to: Spencer Hansen, College of Education and Human Services, Utah State University, 2865 Old Main Hill, Logan, UT 84322-2865. E-mail: sdhansen@dsdmail.net.

MANUSCRIPT:

Initial Acceptance:

02/09/04

Final Acceptance:

09/10/04 